\title{
Gas Leakage Detection and Alert System using IoT
}

\author{
Sayali Joshi, Shital Munjal, Prof. Uma B. Karanje
}

Computer Engineering, Marathwada Mitra Mandal Institute of Technology, Lohgaon, Pune, Maharashtra, India

\begin{abstract}
The Internet of things (IoT) is the system of gadgets, vehicles, and home machines that contain hardware, programming, actuators, and network which enables these things to interface, collaborate and trade information. IoT includes broadening Internet network past standard device, for example, work areas, workstations, cell phones and tablets, to any scope of generally stupid or non-web empowered physical device and ordinary articles. Installed with innovation, these gadgets can convey and connect over the Internet, and they can be remotely observed and controlled [1]. The meaning of the Internet of things has advanced because of union of numerous innovations, ongoing examination, AI, ware sensors, and implanted frameworks. Conventional fields of installed frameworks, remote sensor systems, control frameworks computerization (counting home and building mechanization), and others all add to empowering the Internet of things. A gas spill alludes to a hole of petroleum gas or different vaporous item from a pipeline or other regulation into any territory where the gas ought not be available. Since a little hole may steadily develop a hazardous convergence of gas, spills are perilous. Notwithstanding causing flame and blast dangers, holes can slaughter vegetation, including huge trees, and may discharge amazing ozone harming substances to the environment.
\end{abstract}

Keywords: IOT, MQ5 sensor, Arduino module, GSM networks.

\section{INTRODUCTION}

The Internet of Things is a developing theme of specialized, social, and monetary centrality. Customer items, tough goods, cars and trucks, modern and utility segments, sensors, and other regular articles are being joined with Internet availability and amazing information systematic capacities that guarantee to change the manner in which we work, live, and play. Projections for the effect of IoT on the Internet and economy are amazing, with some foreseeing upwards of 100 billion associated IoT gadgets and a worldwide financial effect of more than $\$ 11$ trillion by 2025 . The Internet of Things (IoT) is an essential theme in innovation industry, strategy, and designing circles [1]. This innovation is encapsulated in a wide range of arranged items, frameworks, and sensors, which exploit headways in processing power, gadgets scaling down, and organize interconnections to offer new capacities. The expansive scale usage of IoT gadgets guarantees to change numerous parts of the manner in which we live. For shoppers, new IoT items like Internet-empowered machines, home mechanization parts, and vitality the executive's gadgets are pushing us toward a dream of the "savvy home", offering greater security and vitality effectiveness. IoT frameworks like arranged vehicles, savvy traffic frameworks, and sensors implanted in streets and scaffolds draw us nearer to "brilliant urban areas", which help limit clog and vitality utilization. IoT innovation offers the likelihood to change horticulture, industry, and vitality creation and dissemination by expanding the accessibility of 
data along the esteem chain of generation utilizing arranged sensors [3].

\section{METHODS AND MATERIAL}

System: Input, Output, Function, Success, Failure

Input: Sensor data signal which is not regular or Change in Signal

Output: End User get informed with alert buzzer and Display to LCD

\section{Functions:}

1. Access ():- In this module we are going to access the feature provided by the module which Will include Sensor data access.

2. Control ():-In this module we are controlling the Alert System by using System which is connected to hardware or sensor data.

3. Broadcast ():-In this module we are going to broadcast the alert Display to LCD.

4. Success Conditions:

1. If such data which is received through sensors are not stable or are more than threshold it will predict that there is leakage situation

5. Failure Conditions: Desired output is not generated due to following failures.

1. Software Failure

2. Hardware Failure

3. Network Connection Failure

\section{HARDWARE INFORMATION:}

\section{Arduino Uno}

The Arduino Uno is a microcontroller board based on the ATmega328 (datasheet). It has 14 digital input/output pins (of which 6 can be used as PWM outputs), 6 analog inputs, a $16 \mathrm{MHz}$ ceramic resonator, a USB connection, a power jack, an ICSP header, and a reset button. It contains everything needed to support the microcontroller; simply connect it to a computer with a USB cable or power it with a AC-to-DC adapter or battery to get started.
The Uno differs from all preceding boards in that it does not use the FTDI USB-to-serial driver chip. Instead, it features the Atmega16U2 (Atmega8U2 up to version R2) programmed as a USB-to-serial converter.

\section{LCD (Liquid Crystal Display)}

LCD stands for Liquid Crystal Display. LCD is finding wide spread use replacing LEDs (seven segment LEDs or other multi segment LEDs) because of the following reasons:

1. The declining prices of LCDs.

2. The ability to display numbers, characters and graphics. This is in contrast to LEDs, which are limited to numbers and a few characters.

3. Incorporation of a refreshing controller into the LCD, thereby relieving the CPU of the task of refreshing the LCD. In contrast, the LED must be refreshed by the CPU to keep displaying the data.

\section{BUZZER}

A buzzer or beeper is an audio signalling device, which may be mechanical, electromechanical, or piezoelectric. Typical uses of buzzers and beepers include alarm devices, timers and confirmation of user input such as a mouse click or keystroke. The first electric buzzer was invented in 1831 by Joseph Henry. They were mainly used in early doorbells until they were phased out in the early 1930s in favor of musical chimes, which had a softer tone. Piezoelectric buzzers, or piezo buzzers, as they are sometimes called, were invented by Japanese manufacturers and fitted into a wide array of products during the $1970 \mathrm{~s}$ to $1980 \mathrm{~s}$. This advancement mainly came about because of cooperative efforts by Japanese manufacturing companies. In 1951, they established the Barium Titanate Application Research Committee, which allowed the companies to be "competitively 
cooperative" and bring about several piezoelectric innovations and inventions.

\section{Bluetooth Module:}

SIM900 GSM Module - This means the module supports communication in $900 \mathrm{MHz}$ band. We are from India and most of the mobile network providers in this country operate in the $900 \mathrm{MHz}$ band. If you

\section{Simulation Diagram}

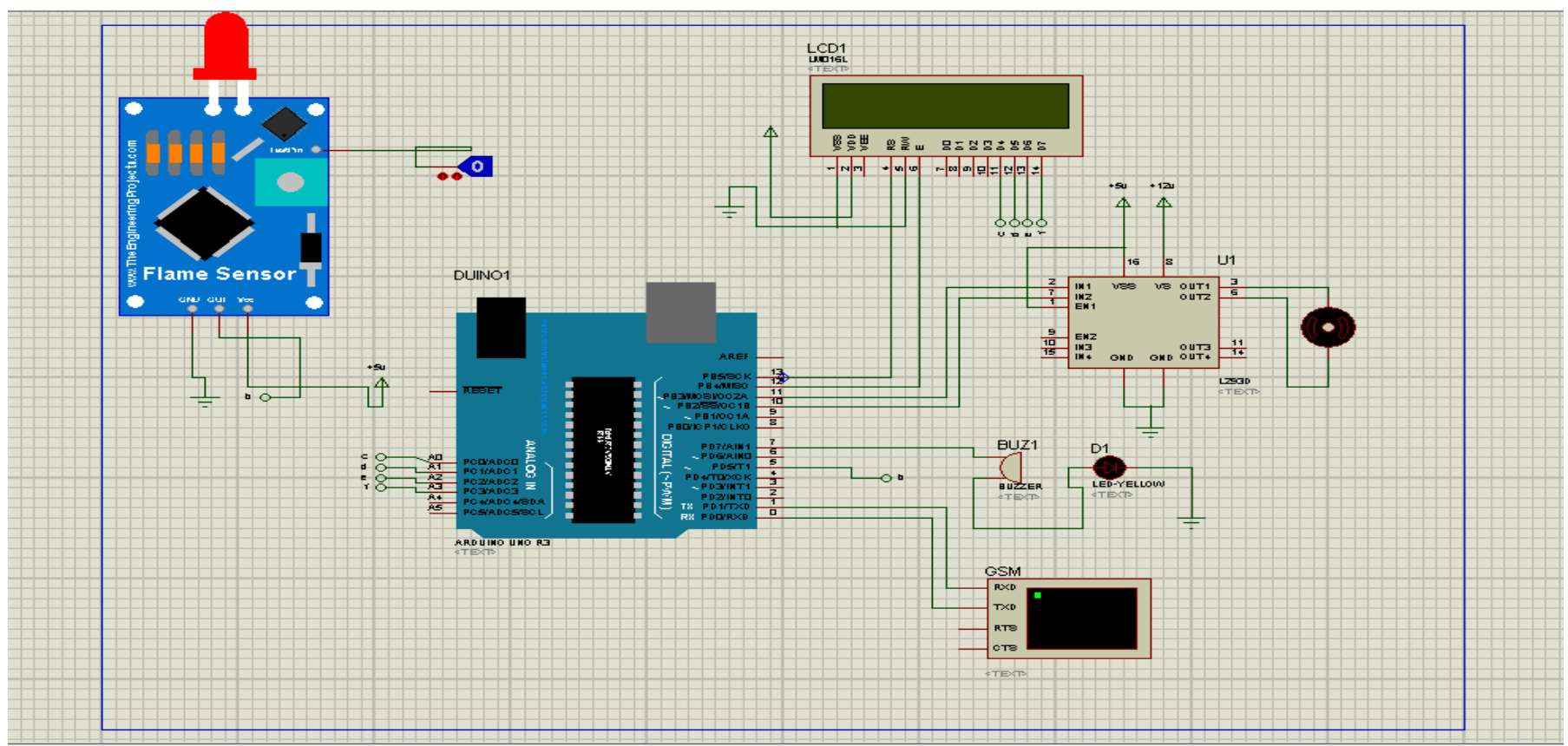

Fig.1: Simulation Diagram

III. LITERATURE SURVEY
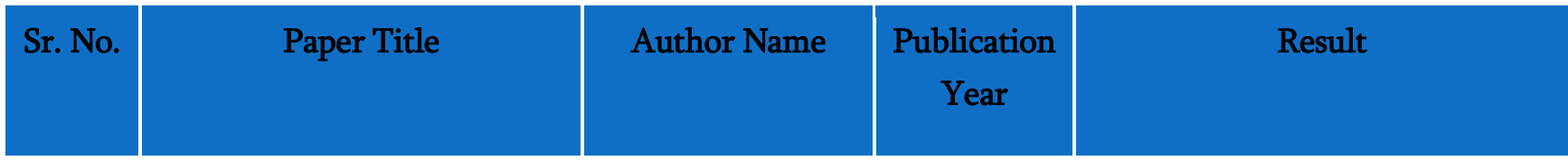

1

Internet of Things (IOT)

Rohan Chandra

2017

Based Gas Leakage

Pandey, Manish

Monitoring and Alerting

Verma, Lumesh

System with MQ-2 Sensor

Kumar Sahu are from another country, you have to check the mobile network band in your area. A majority of United States mobile networks operate in $850 \mathrm{MHz}$ band (the band is either $850 \mathrm{MHz}$ or $1900 \mathrm{MHz}$ ). Canada operates primarily on $1900 \mathrm{MHz}$ band. 


\begin{tabular}{|c|c|c|c|c|}
\hline 2 & $\begin{array}{l}\text { Gas Leakage Detection and } \\
\text { Smart Alerting and } \\
\text { Prediction Using IoT }\end{array}$ & $\begin{array}{l}\text { Asmita Varma, } \\
\text { Prabhakar S, } \\
\text { Kayalvizhi } \\
\text { Jayavel }\end{array}$ & 2017 & $\begin{array}{l}\text { The proposed gas leakage } \\
\text { detector is promising in the } \\
\text { Field of safety. }\end{array}$ \\
\hline 3 & \begin{tabular}{lrr} 
IOT Based & Gas & Leakage \\
Detection & System & with \\
Database & \multicolumn{2}{c}{ Logging, } \\
Prediction & and & Smart \\
Alerting & &
\end{tabular} & $\begin{array}{l}\text { Chaitali Bagwe, } \\
\text { Vidya Ghadi, } \\
\text { Vinayshri Naik, } \\
\text { Neha Kunte }\end{array}$ & 2018 & $\begin{array}{l}\text { The system provides constant } \\
\text { monitoring and detection of gas } \\
\text { leakage along with storage of } \\
\text { data in database for predictions } \\
\text { and analysis. The IOT } \\
\text { components used helps in } \\
\text { making the system much more } \\
\text { cost effective in comparison } \\
\text { with traditional Gas detector } \\
\text { systems. }\end{array}$ \\
\hline 4 & $\begin{array}{l}\text { Internet of Things (IoT) } \\
\text { Based Gas Leakage } \\
\text { Monitoring and Alerting } \\
\text { System with Mq-6 Sensor }\end{array}$ & $\begin{array}{lr}\text { Rohan } & \text { Chandra } \\
\text { Pandey, Manish } \\
\text { Verma, Lumesh } \\
\text { Kumar Sahu, } \\
\text { Saurabh } \\
\text { Deshmukh }\end{array}$ & 2018 & $\begin{array}{l}\text { A discussion on how the aims } \\
\text { and objectives are met is } \\
\text { presented. An overall } \\
\text { conclusion IOT based toxic gas } \\
\text { detector is it has become more } \\
\text { efficient, more applicable to } \\
\text { today's applications and } \\
\text { smarter. }\end{array}$ \\
\hline 5 & $\begin{array}{l}\text { Gas Leakage Detection and } \\
\text { Smart Alerting } \\
\text { System Using IoT }\end{array}$ & $\begin{array}{l}\text { Shital Imade, } \\
\text { Priyanka } \\
\text { Rajmanes, } \\
\text { Aishwarya Gavali }\end{array}$ & 2018 & $\begin{array}{l}\text { In this paper we use IOT } \\
\text { technology for enhancing the } \\
\text { existing safety standards. While } \\
\text { making this prototype has been } \\
\text { to bring a revolution in the } \\
\text { field of safety against the } \\
\text { leakage of } \\
\text { harmful and toxic gases }\end{array}$ \\
\hline
\end{tabular}

Table.1: Literature Survey

\section{PROPOSED SYSTEM}

We design and develop an propose system which include some safety factors. A safety has been a major issue in today's day to day life. LPG and CNG i.e. petroleum gas and compressed natural gas are most commonly used in residential and commercial places for cooking purpose and in various vehicles as a replacement for costly fuels like diesel, petrol [7]. These gases are filled in cylinders which are easily un-damageable. But leakage can take place through pipes or regulators or knobs which may cause accidents like suffocation, uneasiness or sometimes 
may catch fire and short circuit as well. The main aim of this project is developing a system that can detect gas leakage [8]. On detection it will send an alert SMS and the gas supply knob of cylinder will be switched off automatically.

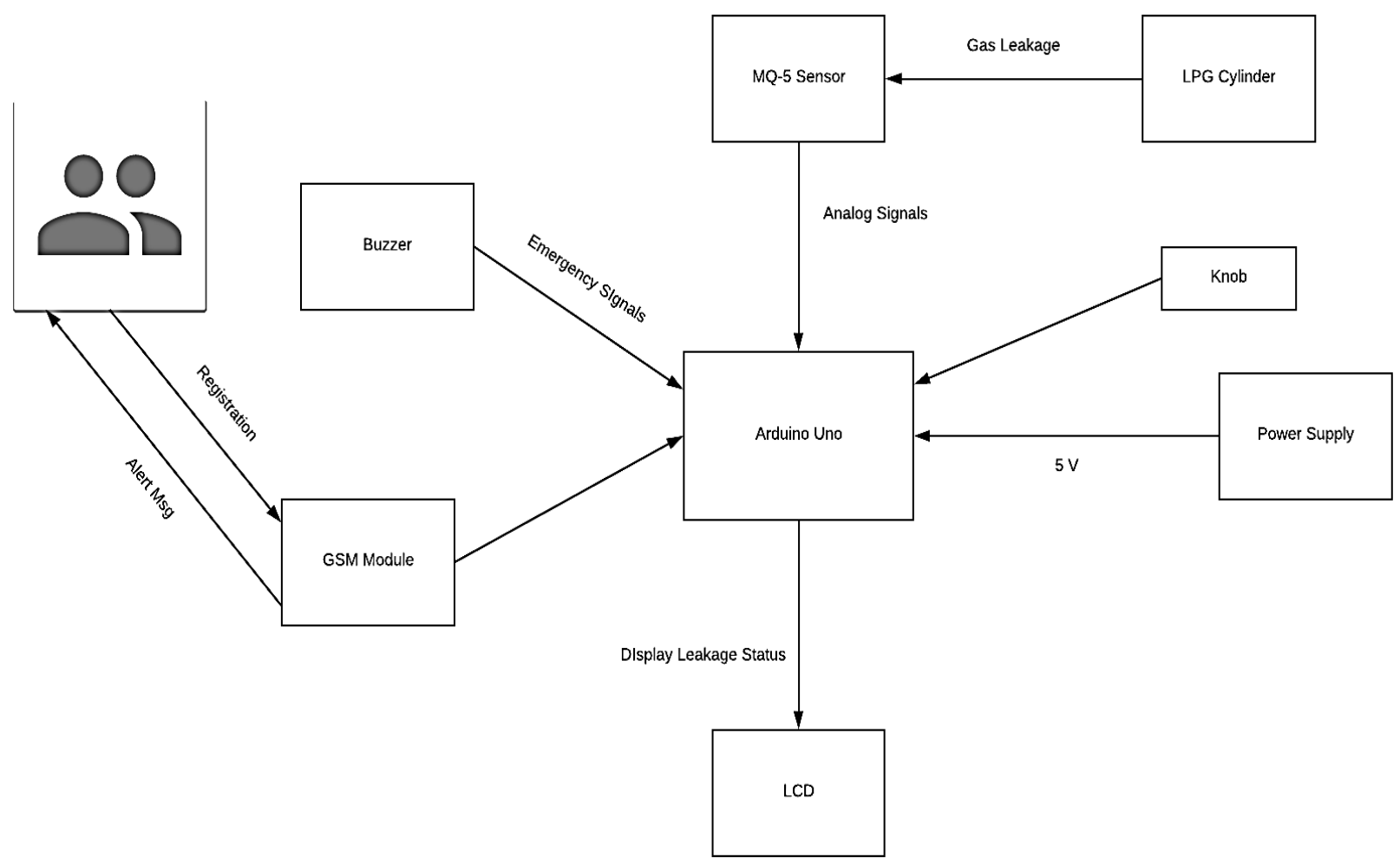

Fig.2: System Architecture

\section{CONCLUSION}

The advantage of this simple gas leak detector is its simplicity and its ability to warn about the leakage of the LPG gas [11]. This system uses GSM technique to send alert massage to respective person if no one is there in the house and then gas leaks occurs, GSM module is there to send immediate messages to the respective person regarding the gas leak [13]. The main advantage of this system is that it off the regulator knob of the cylinder automatically when gas leakage detected.

\section{REFERENCES}

[1]. Mr. Sameer Jagtap, Prajkta Bhosale, Priyanka Zanzane, Jyoti Ghogare, "LPG Gas Weight and
Leakage Detection System Using IoT", International Journal for Research in Applied Science \& Engineering Technology", Volume 4, Issue 3, March 2016, Pg - 716 to 720.

[2]. Arun Raj, Athira Viswanathan, Athul T S, "LPG Gas Monitoring System”, International Journal of Innovative Technology and Research, Volume 3, Issue 2, February 2015, Pg - 1957 to 1960.

[3]. S Shyamaladevi, V. G. Rajaramya, P. Rajasekar, P. Sebastin Ashok, "ARM7 based automated high-performance system for lpg refill booking \& leakage detection", Journal of VLSI Design and Signal Processing", Volume 3, Issue 2, 2014.

[4]. S. Sharma, V. N. Mishra, R. Dwivedi, R. Das, "Classification of gases/odours using Dynamic Response of Thick Film Gas Sensor Array", IEEE Conference on Sensors Journal, 2013. 
[5]. Rajeev B. Ahuja, Jayant K. Dash, Prabhat Shrivastava, "A comparative analysis of liquefied petroleum gas (LPG) and kerosene related burns", Burns, Volume 37, Issue 8, December 2011, Pg - 1403 to 1410.

[6]. Prof. Pankaj C. Warule, Shivam Upadhyay, Snehal S. Shelke, Sumitra K. Khandade, "LPG Detection, Metering and Control System Using Microcontroller", IJARIIE, Volume 2, Issue 2, 2016, Pg -648 to 652.

[7]. Ankit Sood, Babalu Sonkar, Atul Ranjan, Mr. Ameer Faisal, "Microcontroller Based LPG Gas Leakage Detector Using GSM Module", International Journal of Electrical and Electronics Research, Volume 3, Issue2, AprilJune 2015, Pg - 264 to 269.

[8]. Ashish Shrivastava, Ratnesh Prabhakar, Rajeev Kumar, Rahul Verma, "GSM Based Gas Leakage Detection System", International Journal of Technical Research and Applications", Volume 1, Issue2, May- June 2013, Pg - 42 to 45.

[9]. Shivalingesh B. M, Ramesh C, Mahesh S. R, Pooja R, Preethi K. Mane, Kumuda S, "LPG Detection, Measurement and Booking System", IJRSI, Volume 1, Issue 4, November 2014, Pg 7 to 10 .

[10]. C. Selvapriya, S. Prabha Sathya, M. Abdulrahim, C. K. Aarthi, "LPG Leakage Monitoring and Multilevel Alerting System", International Journal of Engineering Sciences \& Research Technology, Volume 2, Issue 11, November 2013, Pg - 3287 to 3290.

[11]. H. Huang, H. Bainand, S. Zhu, "A Greenhouse Remote Monitoring System Based on GSM", in Proceedings of IEEE International Conference on Information Management, 2011, Pg - 357 to 360 .

[12]. Lianos, M. and Douglas, M. (2000) Dangerization and the End of Deviance: The
Institutional Environment. British Journal of Criminology, 40, 261-278.

[13]. J. Tsado, O. Imoru, S.O. Olayemi, "Design and construction of a GSM based gas leak Alert system", IEEE Transaction, IRJEEE Vol. 1(1), pp. 002-006, September, 2014.

[14]. D. Surie, O. Laguionie, T. Pederson, "Wireless sensor networking of everyday objects in a smart home environmentl, Proceedings of the International Conference on Intelligent Sensors", Sensor Networks and Information Processing- ISSNIP- 2008, pp. 189 - 194

[15]. http://dx.doi.org/10.4236/ait.2011.11002 5Aggarwal, R. and Lal Das, M. (2012) RFID Security in the Context of "Internet of Things". First International Conference on Security of Internet of Things, Kerala, 17-19 August 2012. http://dx.doi.org/10.1145/2490428.2490435

[16]. Kosmatos, E.A., Tselikas, N.D. and Boucouvalas, A.C. (2011) Integrating RFIDs and Smart Objects into a Unified Internet of Things Architecture. Advances in Internet of Things: Scientific Research.

[17]. M. Eisenhauer, P. Rosengren, P. Antolin, "A Development Platform for Integrating Wireless Devices and Sensors into Ambient Intelligence Systems", pp.1-3

\section{Cite this article as :}

Sayali Joshi, Shital Munjal, Prof. Uma B. Karanje, "Gas Leakage Detection and Alert System using IoT", International Journal of Scientific Research in Science and Technology (IJSRST), Online ISSN : 2395-602X, Print ISSN : 2395-6011, Volume 6 Issue 2, pp. 445-450, March-April 2019. Available at doi : https://doi.org/10.32628/IJSRST196256 Journal URL : http://ijsrst.com/IJSRST196256 